\title{
Preface for the thematic issue: IMSD 2012
}

\author{
Peter Eberhard • Pascal Ziegler
}

Received: 14 March 2013 / Accepted: 6 May 2013 / Published online: 21 May 2013

(C) Springer Science+Business Media Dordrecht 2013

The Second Joint International Conference on Multibody System Dynamics (IMSD 2012) was held May 29 to June 1, 2012 at the University of Stuttgart, Germany. It served as a meeting point for the international multibody community and provided an opportunity to exchange high-level, current information on the theory and applications of multibody systems. As a rapidly growing branch of mechanics, multibody system dynamics is seeing more and more use, and is becoming increasingly important in the development of complex engineering systems. The continual new challenges faced by the IMSD community demand productive exchange of ideas and a spirit of cooperation is encouraged.

The conference was attended by 301 participants from 29 countries and 199 talks were delivered. Institutional sponsors of the IMSD are the ASME (American Society of Mechanical Engineers), IFToMM (International Federation for the Promotion of Mechanism and Machine Science), IUTAM (International Union of Theoretical and Applied Mechanics), JSME (Japanese Society of Mechanical Engineers), KSME (Korean Society of Mechanical Engineers).

Based on recommendations of the members of the Scientific Committee and the Session Organizers, authors giving insight into advanced topics of recent multibody dynamics were invited to submit papers. All these papers have been strictly peer-reviewed to guarantee high quality and a good representation of various fields of multibody dynamics. The papers now published in this Thematic Issue are selected, among those accepted, in order to represent the most recent challenges and developments in Multibody Dynamics in its various fields.

We wish you a most interesting reading.

P. Eberhard $(\bowtie) \cdot$ P. Ziegler

Institute of Engineering and Computational Mechanics, University of Stuttgart, Pfaffenwaldring 9, 70569 Stuttgart, Germany

e-mail: peter.eberhard@itm.uni-stuttgart.de

url: www.itm.uni-stuttgart.de 